\title{
A práxis no trabalho de campo: uma experiência em biogeografia
}

\author{
The praxis in the fieldwork: an experience in biogeography
}

\author{
Luisa Renata Tacca Anghinoni', Pedro Murara", Alana Rigo Deon"I
}

\begin{abstract}
RESUMO
O texto objetiva refletir sobre como o trabalho de campo pode servir como recurso metodológico para a práxis do profissional da Geografia. Para isso, apresentamos um roteiro metodológico de trabalho de campo desenvolvido em âmbito da disciplina de Biogeografia na cidade de Florianópolis, que se pautou em três fases: gabinete (discussão da ementa da disciplina e levantamento de materiais bibliográficos e cartográficos acerca da área de estudo), trabalho de campo in loco (observação, descrição e interpretação dos dados) e o laboratório (análise, compreensão e representação refletidas através do relatório de campo). Por fim, as reflexões tidas a partir do trabalho de campo mostram que o território está em constante transformação em seus vários aspectos sociais, culturais, e econômico, por isso, entender como essas transformações se materializam nos lugares ainda continua sendo esse essencial para a formação de profissionais críticos e reflexivos acerca do seu campo de estudo, na perspectiva da práxis.
\end{abstract}

Palavras-chave: Biogeografia; Ensino de Geografia; Práxis; Trabalho de Campo

\section{ABSTRACT}

The text aims to reflect on how fieldwork can serve as a methodological resource for teacher praxis. For this, we present a methodological path developed within the scope of Biogeography in the city of Florianópolis, which was based on three phases: office (discussion of the menu of the discipline and collection of bibliographic and cartographic materials about the study area), fieldwork (observation, description and interpretation of data) and the laboratory (analysis, understanding and representation reflected in the field report). Finally, the reflections taken from the field work show that the territory is constantly changing in its various social, cultural, and economic aspects, so to understand how these transformations materialize in the places still remains the essential one for the formation of critical and reflective professionals about their field of study from the perspective of praxis.

Keywords: Biogeography; Fieldwork ; Geography Teaching; Praxis

'Acadêmica do curso de Geografia-Licenciatura da Universidade Federal da Fronteira Sul - Campus Erechim. Bolsista do Programa Residência Pedagógica. E-mail: luisa_tacca@hotmail.com ORCID: https://orcid.org/0000-0003-0834-1654

"Professor Adjunto II da Universidade Federal da Fronteira Sul (UFFS), campus Erechim/RS.. E-mail: pedro.murara@uffs.edu.br ORCID: http://orcid.org/0000-0002-6063-3374

I"Doutoranda em Educação nas Ciências. Mestra em Educação nas Ciências: área de Concentração Geografia pela Unijui -RS. Email: alanardeon@gmail.com ORCID: https://orcid.org/0000-0002-5930-6368 


\section{INTRODUÇÃO}

O trabalho de campo na Ciência Geográfica se constitui enquanto etapa inerente da formação do profissional da geografiai', seja ela na habilitação licenciatura ou bacharelado. O campo envolve uma tríade de etapas: o gabinete, o campo in loco e o laboratório, em que o uso de técnicas na formação do Geógrafo é desenvolvido pelo profissional, com a finalidade de conhecer, observar, descrever, interpretar, analisar, compreender e representar (CALLAl; MORAES, 2017) o objeto/área de estudo.

O gabinete constitui a primeira etapa do trabalho de campo, e é entendido como a fase de definição dos objetivos, organização e planejamento das atividades a serem desenvolvidas (VENTURI, 2011). Dessa forma, compreende a investigação prévia da área de estudo, organização de roteiro a ser seguido, seleção de referenciais teóricos e mapas que contribuirão para a leitura geográfica e cartográfica dos fenômenos.

A atividade de campo, em sua excelência, envolve o contato com a realidade do objeto a ser conhecido/investigado (VENTURI, 2011). Uma vez efetuado a etapa anterior, de gabinete, o campo será o local selecionado onde o professor/ pesquisador irá, por meio da aplicação de técnicas ou intermediado por estas, coletar e/ou observar o seu objeto de estudo. Na formação do profissional em Geografia, o campo também é entendido para além da coleta de dados e informações para a pesquisa científica. Neste caso, o campo se constitui como aula de campo, no qual o aluno, acompanhando do professor irá percorrer diferentes ambientes e localidades, sejam elas focadas em aspectos naturais, urbanos, rural ou dependendo da temática e objetivo da atividade a ser desenvolvida.

Desta forma, os alunos praticam principalmente a observação dos diferentes espaços orientados pelos conceitos trabalhados e desenvolvidos em sala de aula. Portanto, o campo se torna, em certa medida, uma extensão da sala 
de aula, bem como, o laboratório de pesquisa do aluno, uma vez que, fora da sala de aula física, o estudante irá usar de técnicas de observação e manuseio de instrumentos para captar e elaborar a descrição e a interpretação da realidade em análise e foco do objeto de investigação. E ainda, será na aula de campo que o aluno terá condições para desenvolver a análise geográficaii in loco, objetivando compreender a integração dos diferentes conceitos, elementos e processos que envolvem a produção do espaço geográfico.

A terceira etapa, envolve o laboratório, sendo o local físico no qual equipado com instrumental específico serão desenvolvidas atividades posteriores ao campo como, por exemplo, análise, compreensão e representação das informações coletas realizadas na etapa do trabalho de campo (VENTURI, 2011). Estas serão refletidas através da produção de um relatório de campo, que explicitará as relações estabelecidas entre os conceitos científicos e as análises em campo.

Importante destacar que essas três etapas: gabinete, campo e laboratório não são necessariamente obrigatórias para o desenvolvimento de uma pesquisa ou para a realização de uma aula de campo. É possível que, por exemplo, a etapa de laboratório seja suprimida diante do foco e do objeto de investigação. Ou ainda, que a etapa de gabinete, seja a etapa última, quando da realização da tríade de etapas apresentadas.

O exemplo de trabalho de campo a ser apresentado foi desenvolvido na disciplina de Biogeografia no curso de Gradação em Geografia - Licenciatura da Universidade Federal da Fronteira Sul, campus Erechim. Dentre as disciplinas que envolvem a formação de professores, o curso delimita que parte da carga horária da formação do estudante seja desenvolvida com trabalhos de campo. Neste sentido, o PPP (2010) do curso salienta a importância da formação do geógrafoprofessor no subsídio de reflexões de cunho teórico e possíveis ações práticas, que levem em consideração à problemática socioambiental no contexto cultural, econômico, político, científico e acadêmico em que os licenciados estão inseridos. 
O trabalho de campo no curso de Geografia tem sido por excelência o espaço/lugar da práxis docente, pois é o momento no qual os alunos conseguem relacionar as discussões teóricas elucidadas nas disciplinas de cunho técnico de sua formação, com as questões de ordem prática que se materializam no espaço geográfico. Esse processo envolve uma atitude teórico-prática humana na busca do entendimento de como ocorre a transformação da natureza e da sociedade (MARX, 1986 apud PIMENTA, 2009, p.95).

É buscando entender as relações entre sociedade e natureza que a Biogeografia, enquanto disciplina tem por objetivo compreender a distribuição e espacialização dos seres vivos no contexto histórico e ecológico. Ou seja, estuda a distribuição das espécies animais e vegetais, o que the confere como característica uma visão sob o foco ambiental na Geografia (AUTOR, 2016).

A Biogeografia é dividida tradicionalmente em duas grandes áreas: a Fitogeografia, que versa sobre a distribuição das espécies vegetais em diversas regiões do globo, conforme as zonas climáticas e fatores do meio físico que possibilitam sua adaptação e, a Zoogeografia, que analisa e estuda a distribuição e organização espacial das espécies animais (FURLAN, 2005).

Neste sentido o trabalho de campo na disciplina de Biogeografia é importante no processo de ensino-aprendizagem pois com este movimento de análise in loco, mediada pela teoria são conhecidas as diferenças físicas e ambientais, sociais, bem como, os padrões distintos de vegetação que podem e irão influenciar na distribuição das espécies animais. E ainda, envolve a coleta de materiais vegetais e minerais de determinada área de estudo afim de reconhecer os padrões de distribuição espacial das espécies.

Considerando esses elementos, o presente artigo foi desenvolvido com o intuito de apresentar uma possibilidade de roteiro metodológico para o trabalho de campo em Biogeografia. Desse modo, objetiva-se refletir sobre como o trabalho de campo pode servir como recurso metodológico para a práxis docente, apresentando algumas considerações no âmbito da Biogeografia, 
elencando as principais características físicas da área de estudo, a cidade de Florianópolis, bem como as técnicas de análise aplicadas e utilizadas com base e a luz do referencial teórico da disciplina. Para descrever essas ações, primeiramente apresentamos os caminhos trilhados mostrando como ocorreu a etapa de planejamento para o desenvolvimento do trabalho de campo, e após, descrevemos o passo a passo das atividades desenvolvidas no campo, os lugares visitados in loco, fazendo reflexões sobre elementos que emergiram da prática.

\section{CAMINHOS TRILHADOS}

Os trabalhos de campo que ocorrem em âmbito do curso de geografia na UFFS têm o caráter de integrar as várias disciplinas da fase/semestre em curso. Nesse sentido, o desenho metodológico empregado para o desenvolvimento do trabalho de campo consistiu em leituras de bibliografias que fazem parte da ementa da disciplina de biogeografia trabalhadas em sala de aula. É importante que o trabalho de campo ocorra em um momento no qual grande parte dos conteúdos e conceitos já tenham sido trabalhados em aula para que possam desenvolvidos e aprofundados no campo.

Essa foi a primeira etapa para o desenvolvimento do campo, e envolveu o trabalho de gabinete, nos qual os docentes responsáveis pelas disciplinas, em conjunto com os alunos traçaram objetivos, metas e trajetos que seria realizado em campo. Toda a estrutura e infraestrutura que envolve a atividade é elaborada e construída com os alunos. Nos dias anteriores a efetivação do trabalho de campo, foi efetuada uma aula pré-campo na qual os docentes fazem uma revisão do roteiro repassando ponto a ponto o que será desenvolvido.

A segunda parte foi o estudo de campo, que procurou aprofundar os estudos propostos, tendo como prospecto de análise o espaço in loco. Gil (p.72) destaca que "num estudo de campo, a ênfase poderá estar, por exemplo, na análise da estrutura do poder local ou das formas de associação verificadas entre 
seus moradores". Dessa forma, a estudo de campo aqui apresentado, foi realizado seguindo um roteiro pré-estabelecido a partir da visita em alguns pontos da cidade de Florianópolis. Esses foram selecionados de acordo com a temática a ser trabalhada, bem como, da disponibilidade de contato e efetuar a visita nos pontos de acordo com a disponibilidade do local.

A seleção do município de Florianópolis para a realização do trabalho de campo de Biogeografia se justificou pela presença de espaços de naturezas protegidas (ENPS) na llha de Santa Catarina (FERRETTI, 2013). O município apresenta em seus $421,5 \mathrm{~km}^{2}$, uma diversidade de paisagens que resultam em uma riqueza de habitats naturais. Por se tratar de estudantes que realizam sua formação no interior do continente, a opção de visitar uma capital com as características citadas anteriormente e que se localiza no litoral possibilita que conceitos e realidades in loco não identificadas pelos discentes sejam desenvolvidas durante as aulas de campo.

Muito embora a ilha de Santa Catarina apresente 29 ENPs, criados legalmente, alguns como Unidades de Conservação, representando 73\%, as Áreas de Preservação Permanente Municipal 23\% e uma unidade de conservação diferenciada, a Unidade de Conservação Ambiental Desterro com 4\% do total das áreas preservadas, realizamos visita apenas em quatro ENPs (figura 1), estas selecionadas a partir da viabilidade de visitação e acompanhamento técnico. Conforme pode ser observado na figura 1, embora a visita tenha se restringido à quatro espaços de naturezas protegidas, durante o trajeto entre essas, foi possível visualizar outras ENPs.

Fizeram parte do trajeto em campo: 2.1. Companhia de Melhoramento da Capital - COMCAP e Museu do lixo; 2.2. Manguezal do Itacorubi; 2.3. Parque 
Municipal Lagoa do Peri; 2.4. Projeto Tamar; 2.5. Costão do Santinho/Museu ao ar livre, e 2.6. Parque do Rio Vermelho.

Figura 1 - Unidades de Conservação e área de preservação permanentes municipais na ilha de Santa Catarina.

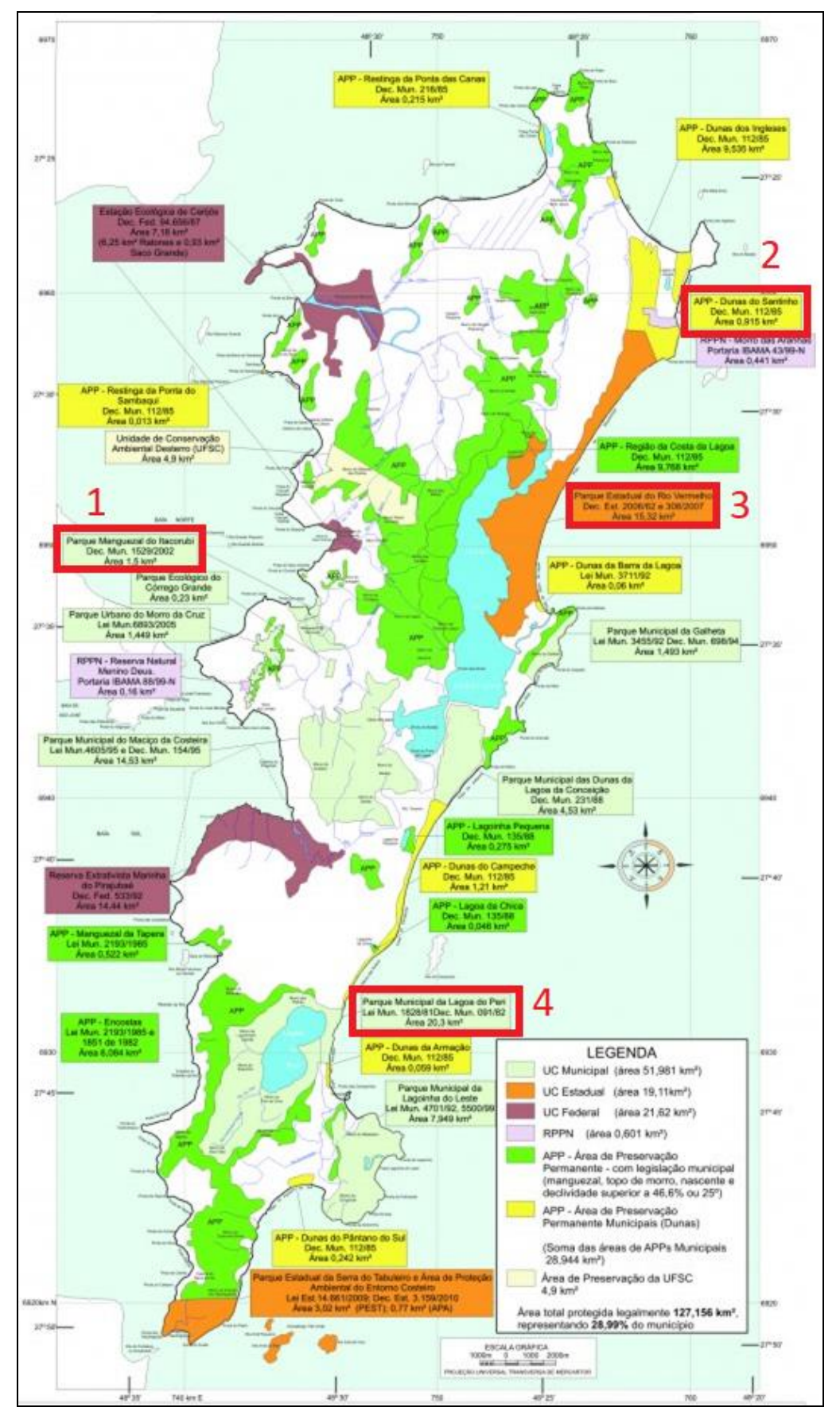

Fonte: Ferreti (2013) 
Nos pontos visitados foram empregadas as técnicas de observação, descrição, interpretação, para posterior análise, compreensão e representação dos fenômenos apresentados na construção do relatório de campo, baseadas na compreensão de Callai e Moraes (2017, p.94), conforme mostra o quadro 1 a seguir:

\section{Quadro 1 - Roteiro Metodológico do Trabalho de Campo}

\begin{tabular}{|l|l|}
\hline Gabinete & $\begin{array}{l}\text { Trabalho de discussão sobre os conceitos bases que } \\
\text { sustentam a biogeografia. } \\
\text { Levantamento de material bibliográfico e cartográfico } \\
\text { acerca da área de estudo in loco. }\end{array}$ \\
\hline Trabalho de Campo & $\begin{array}{l}\text { Emprego de técnicas de observação das características } \\
\text { da área de estudo, considerando a sua localização } \\
\text { geográfica. } \\
\text { Descrição das observações, indicando os detalhes } \\
\text { visíveis e também os ocultos. } \\
\text { E Interpretação que busca conhecimentos/conceitos } \\
\text { que auxiliem no entendimento do que foi observado. }\end{array}$ \\
\hline Laboratório/sistematização & $\begin{array}{l}\text { Essa etapa envolve o trabalho de análise, compreensão } \\
\text { e representação das informações observadas e } \\
\text { descritas in loco refletidas através do relatório de } \\
\text { campo. } \\
\text { A análise busca sistematizar as informações produzidas, } \\
\text { contextualizando-as em espaços maiores, e na história, } \\
\text { na vida das pessoas, na organização e acesso aos bens. } \\
\text { A compreensão busca dar sentido ao que foi } \\
\text { observado, tendo em vista os entendimentos que } \\
\text { podem ser produzidos. A partir da indagação } \\
\text { procurando encontrar as explicações e gerando novas } \\
\text { indagações. } \\
\text { E a representação se dá através da representação do } \\
\text { espaço estudado através da abstração. }\end{array}$ \\
\hline
\end{tabular}

Fonte: Os autores, 2018.

Pautado nesses pressupostos que constituem a análise geográfica, com base nas bibliografias trabalhadas na disciplina de Biogeografia e em pesquisas bibliográficas, o trabalho de campo ajudou na compreensão dos fatores que interferem nos processos ou que influenciam na distribuição espacial das espécies encontradas. Foram utilizadas informações coletadas em campo, assim, como, contato com representantes locais (professores da UFSC, por exemplo) especializados na área. 


\section{O TRABALHO DE CAMPO EM BIOGEOGRAFIA: RESÍDUOS, POLUIÇÃO, PRESERVAÇÃO E EDUCAÇÃO AMBIENTAL}

\subsection{Comcap - Companhia de Melhoramento da Capital e Museu do Lixo}

Com base nestas considerações iniciais esta exposição tem por objetivo evidenciar a importância dos trabalhos de campo na disciplina de Biogeografia e para isto foi realizado observações, descrições e interpretações nas áreas de conservação e reciclagem em loco da ilha de Florianópolis. O trabalho de campo buscou promover uma conexão dos conteúdos vistos em sala de aula com as características reais da paisagem geográfica, apresentação dos seres vivos e sua organização no espaço a partir de influências bióticas e abióticas presentes no meio estudado/visitado.

Durante a visita na Companhia de Melhoramento da Capital (COMCAP) compreendemos como a empresa se organiza a partir da reciclagem de resíduos sólidos. Durante a visita guiada, nos foi enfatizando a seriedade do problema do “lixo" em Florianópolis. Segundo, profissional da Comcap, responsável pelas visitas no local, os resíduos sólidos são produtos que geram muitas despesas, pois a região da ilha é toda regulamentada por leis de proteção ambiental, por isso, não pode receber aterros, sendo necessário deslocar os resíduos produzidos na llha até os municípios vizinhos com custos que variam no valor de aproximadamente $\mathrm{R} \$ 140,00$ a tonelada. Todavia, os resíduos também geram Iucro a aqueles que trabalham com o processo de reciclagem, e neste, há em torno de 70 profissionais que fazem o trabalho de separação de resíduos, sendo essa uma fonte de renda aos mesmos.

Para a biogeografia, a observação, estudo e prática do processo de reciclagem são fundamentais para desenvolver a consciência para a conservação e preservação do ambiente, ou seja, os conceitos estudados em sala de aula foram visualizados naquele território. No caso do recorte espacial analisado em 
Florianópolis, por se tratar de um local turístico que nas épocas de veraneio atrai milhares pessoas tem contribuído para o aumento da produção de resíduos passando de 480 para 1200 toneladas por dia. Sobre isso, foi possível discutir com os alunos as questões necessárias do planejamento urbano em consonância com a preservação do ambiente.

A companhia conta com um projeto de compostagem de vegetais, executado a partir dos resíduos (restos de alimentos) que, após triturados se transformam em material orgânico sendo utilizado como fertilizante natural para hortas e jardins públicos e privados, diminuindo assim o volume de resíduo (menor quantidade de resíduos deve ser descartada no aterro, diminuindo o valor do transporte) e contribuindo para recuperação de solos de maneira natural, sem adição de insumos.

Outro Projeto desenvolvido pela Comcap com a finalidade de promover a educação ambiental é o Museu do Lixo. O museu resgata os materiais descartados pela população como por exemplo, ferros de passar roupa, computadores, máquinas fotográficas e de costura, aparelhos de telefone, livros entre outros. A partir da separação destes materiais, os gestores criaram um espaço de memória e conscientização sobre o consumismo na sociedade atual. O museu desperta um olhar sobre um estilo de vida expresso pela sociedade atual que fixa padrões de consumo como status social. Nesta etapa, foi possível discutir como o modelo de vida consumista pode ser incompatível com o ciclo natural do ambiente.

Desta forma, foi possível desenvolver com os discentes conceitos de educação ambiental, preservação, conscientização e impacto ambiental, bem como, planejamento urbano, economia solidária e coletividade. Conceitos esses que muitas vezes são teóricos em sala de aula e passam a ser observados e constados in loco por meio da aula de trabalho de campo. 


\subsection{Manguezal Itacurubi}

O manguezal visitado é constituído por três tipos diferentes de vegetação. O mangue vermelho, o mangue amarelo e o mangue branco, que recebem essa classificação devido à sua coloração. As espécies vegetais possuem pneumatóforos, que são raízes especializadas à realização de trocas gasosas com o ambiente. É um importante local de desova de moluscos, crustáceos, peixes, além de pássaros e mamíferos de pequeno e médio porte.

Esta reserva se encontra localizada no centro da ilha e é um ecossistema de transição caracterizado pelo encontro de água doce e salgada, com sedimentos oceânicos e terrestres, assim as espécies de plantas e animais vão se adaptando e transformando o espaço. Como estudado em sala de aula, a observação concretizou o aprendizado visto que o movimento da água do mar é o fator determinante na formação do manguezal, conforme (imagem 2) a seguir:

Figura 2 - Raízes pneumatóforos do mangue branco.

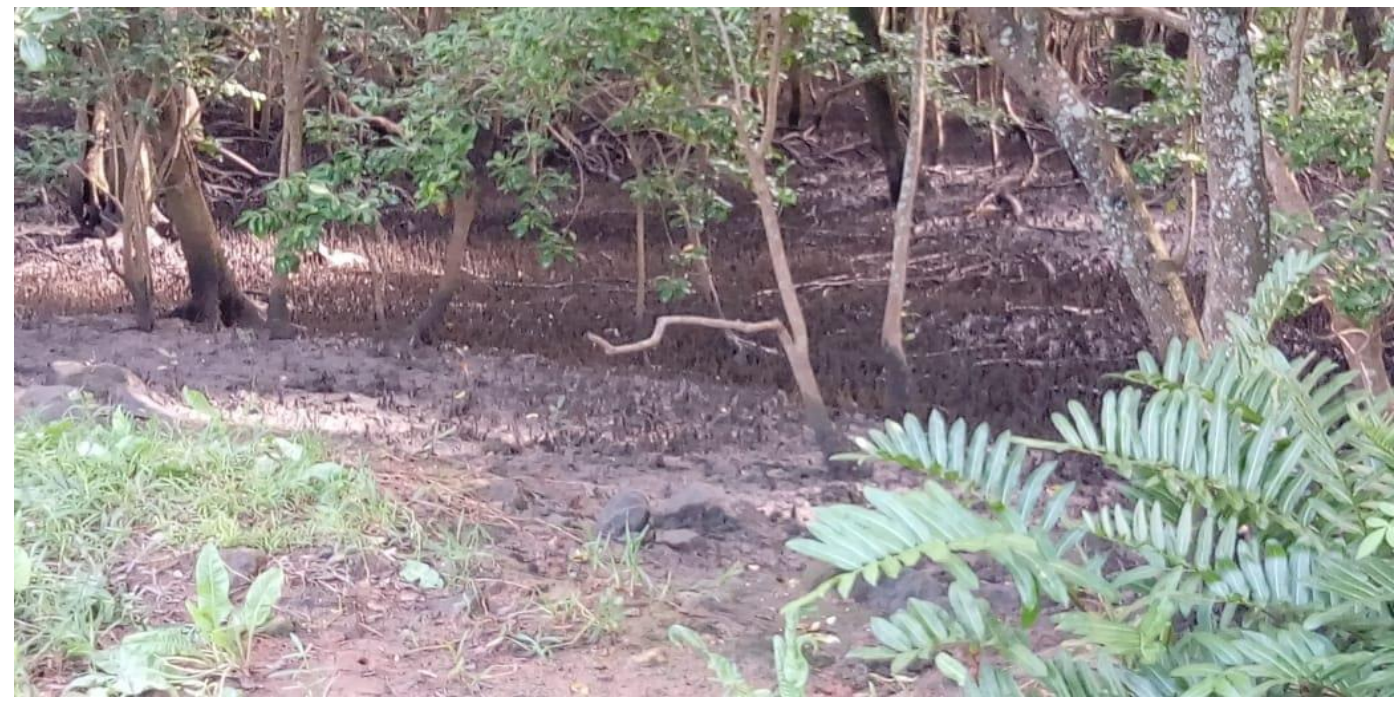

Foto: Os Autores (2018)

Contudo, por se encontrar no centro da ilha, em campo podemos observar que o manguezal recebe lixo e em muitos casos é aterrado para construções. Em campo observamos os diferentes aspectos na paisagem, como o geossistema que 
engloba alguns geofácies e geótopos. Este é um território denso comum, onde se faz a troca e integração dos seres humanos com a natureza litorânea. Sobre isso, Silva (2014, p.27) destaca que a interpretação da natureza por meio do território e da paisagem de forma integrada é capaz de

[...] alcançar as muitas dimensões dos fenômenos geográficos, na procura por uma interpretação de novos paradigmas capazes de sustentar a análise geográfica que atende para os diferentes olhares, perspectivas e dimensões da realidade (SILVA, 2014, p. 27).

Nesse sentido, a paisagem da ilha de Florianópolis é formada por um relevo composto por montanhas que servem como divisores de água, canalizando a água entre as bacias hidrográficas da ilha. Paralelo as montanhas surgem, esparsas planícies a leste e noroeste da ilha, e, no Leste, há presença de dunas, formadas pela ação do vento (CARUSO, 1990). Assim a ilha se destaca por ter a formação diversa de ecossistemas tais como praias, dunas, costões rochosos, restingas, manguezais, lagoas e lagunas e as trilhas onde encontramos registros históricos desde os ancestrais indígenas que marcaram a paisagem com sambaquisiii, proporcionando para o curso de geografia um conhecimento concreto através do trabalho de campo ofertado pelo campus na disciplina de Biogeografia.

Cabe destacar que se trata de um Bioma - Mata Atlântica - o mesmo que os discentes encontram na sua área de inserção na Universidade. Porém, a ausência de mangue no litoral do Rio Grande do Sul, se justifica pela necessidade de, como futuros professores de geografia, conhecerem cada vez mais a diversidade de formações vegetais. Desta forma, para além da visita ao manguezal durante o trajeto percorrido desde a partida da Universidade em Erechim até o destino final em Florianópolis, foi possível destacar e apontar as diferentes formações vegetais que se encontram pelo trajeto, salientando e relacionando seus processos de formação os demais componentes da paisagem. 


\subsection{Parque Municipal da Lagoa do Peri}

O Parque Municipal da Lagoa do Peri, localiza-se na porção Sul da Ilha, junto as praias da armação do Pântano Sul e Morro das pedras distante 24 km do centro da cidade de Florianópolis, possui uma superfície de 20,3km, sendo assim uma das maiores unidades de preservação do município (Figura 1).

A vegetação predominante no parque é a floresta ombrófila densa, cuja formação da área do parque abriga alguns poucos remanescentes de mata primária da Ilha de Santa Catarina. Mas, também encontramos estágios de regeneração da floresta onde houve atividades agrícolas e de exploração seletiva de madeiras, com grande valor econômico durante as décadas de 1930 a 1940, conforme apresentado por Caruso (1990)

Entre a linha de praia e a floresta Atlântica ocorre a vegetação de restinga, típica em solos arenosos, do qual na ilha, predomina a forma arbustiva e pequenas árvores são observadas em localidades onde o solo é rico em húmus possibilitando vegetação de porte médio. A vegetação apresenta folhas com espessura maior que a mata Atlântica e é coberta por uma fina camada de gordura oriunda da salinidade do mar que serve como proteção a folha. As árvores apresentam aspectos de vegetação mesófila e até higrófila, destacandose as bromeliáceas (CARUSO, 1990).

A bacia do Peri é uma área geologicamente constituída pelo complexo cristalino pré-cambriano e por depósitos sedimentares quaternário (SCHEIBE; TEIXEIRA, 1970). A unidade geomorfológica sedimentar caracteriza-se por apresentar uma topografia plana ou suavemente ondulada sendo assim morfologia típica de atuação de processos deposicionais representada pela restinga e planície aluvial com retrabalhamento pela ação marinha, fluvial e eólica.

Sobre esse complexo geológico-geomorfológico, é importante destacar que apenas na década de 1970 percebeu-se a importância da preservação do 
manancial da bacia da Lagoa do Peri, e a partir disso, tomam-se iniciativas para resguardar a área, visto que é a única fonte de água doce potável que abastece em torno de 30.000 mil pessoas da ilha. Vale destacar que na ilha também se encontram lagunas como a da "Conceiçãoiv" que se diferencia da Lagoa do Peri por ter contato com a água salgada do oceano.

Na faixa de praia foi possível observar um banco de areia que se formou possivelmente pelo fluxo e refluxo do mar (ação das ondas). A situação de avanço do mar sobre a vegetação costeira tem aumentado a cada ano, o que se torna um fator de preocupação que requer estudos para minimizar os impactos, bem como iniciativas de proteção da área.

A ilha possui uma "escala" no tipo de vegetação, ou seja, na faixa próxima ao litoral temos a presença de vegetação de restinga, que se forma junto às dunas chamada de vegetação rasteira, estas são caracterizadas como pioneiras e se encontram em áreas arenosas, planícies e cordões arenosos. Após, tem-se a presença de vegetação arbustiva, a mesma tem maior facilidade de desenvolvimento e aderência ao solo, possuindo assim um porte maior que a restinga. Na sequência há vegetação arbórea, ou seja, vegetação de maior porte e floresta ombrófila densa, favorecendo assim a dispersão para a reprodução das espécies.

As características de solo da encosta podem ser analisadas pelo equilíbrio ecológico, dinâmico da relação entre a vegetação cobertura do solo e da cobertura pedológica. Assim sendo, dentro da perspectiva de uma geoecologia o solo não é considerado nem como elemento abiótico e nem como elemento biótico, o solo é considerado como um produto de interface entre interações que acontecem por conta do intemperismo na rocha mãe com matéria orgânica, e é isto, que caracteriza o solo, o qual é formado por essa interação.

Portanto, o solo é um produto de interface e no caso da mata de encosta existe um equilíbrio dinâmico e ecológico, se for retirado a cobertura vegetal deste local vai gerar uma perda de nutrientes no solo, em que o solo vai estar 
exposto ao intemperismo físico por forças das águas fluviais na área de encosta. Tudo isso, associado com a própria dinâmica da gravidade da encosta com ângulo de inclinação teríamos o início de um processo de degradação ambiental.

É importante ressaltar que a trilha que liga a sede do Parque da Lagoa até a Lagoa do Peri foi possível perceber a própria diversidade do sistema e complexo florestal, embora uma parte de área seja de mata secundária neste caso, devido já ter sido alvo da ação antrópica (CARUSO, 1990). Assim mesmo existe um equilíbrio atual em que a manutenção possibilita a dinâmica da biostasia ou sistêmica entre o potencial ecológico e exploração biológica (BERTRAND, 2004).

Devido à complexidade dos geossistemas e as alterações que podem provocar caso seu ciclo natural seja alterado, são criadas pelo poder público, Unidades de Conservaçãov com enfoque em "áreas de grande importância biológica, e prioriza aquelas que estão sob forte pressão antrópica vin.

Estas Unidades, possuem amparo legal na Lei No 9.985, de 19 de julho de 2000, que instaura o Sistema Nacional de Unidades de Conservação (SNUC). Esta lei determina como devem ser criadas e mantidas as unidades de conservação, bem como regulamenta normas e critérios para uso: conservação e uso sustentável dos recursos naturais. De acordo com Silva e Ferreira (2012);

\begin{abstract}
As unidades de conservação no Brasil não estão condicionadas a uma perspectiva exclusivamente ambiental, apresentando formas complexas de relações entre os grupos sociais, o território e o ambiente. No Brasil, a maior parte das Unidades de Conservação quando foram instituídas, eram compostas por populações indígenas, quilombolas e comunidades consideradas tradicionais que foram as mais impactadas com os desdobramentos das políticas ambientais impostas acerca de áreas especialmente protegidas no Brasil.
\end{abstract}

Para o Ministério do Meio Ambiente “A criação de uma UC geralmente se dá quando há uma demanda da sociedade para proteção de áreas de importância biológica e cultural ou de beleza cênica, ou mesmo para assegurar o uso sustentável dos recursos naturais pelas populações tradicionais. É importante que a criação de uma UC leve em conta a realidade ambiental local, para que exerça influência direta no contexto econômico e socioambiental". 
Nesse sentido, as unidades de conservação que é um dos tópicos discutido na disciplina de Biogeografia, ganha notoriedade no trabalho de campo, não só pela visita técnica em um Parque Municipal, mas pelo fato de ser apresentado aos alunos os problemas e os desafios na gestão de uma unidade de conservação.

\subsection{Projeto Tamar}

O projeto Tamar, tem por finalidade a pesquisa, conservação e manejo de tartarugas marinhas no Brasil. A principal missão do projeto Tamar é proteger os cerca de $1.100 \mathrm{~km}$ de praia em nove estados brasileiros. Para isso, promove ações de educação ambiental. O projeto é executado em cooperação entre o Centro Brasileiro de Proteção e Pesquisa das Tartarugas Marinhas-Centro Tamar, vinculado à Diretoria de Biodiversidade do Instituto Chico Mendes da Biodiversidade-ICMBio, órgão do Ministério do Meio Ambiente, e a Fundação PróTamar, instituição não governamental, sem fins lucrativos, fundada em 1988 e considerada de Utilidade Pública Federal desde 1996. O projeto também conta com o patrocínio da Petrobrás vii.

Além disso, funciona como um centro de reabilitação das tartarugas que possibilita a realização desde pequenos procedimentos até cirurgias, biópsias e tratamentos específicos. Segundo dados do projeto a cada cem tartarugas que nascem, somente uma à fase adulta. A sua mortalidade ocorre em grande medida através da ingestão pelas tartarugas de objetos plásticos e metálicos totalmente tóxicos para a fauna.

De acordo com Szpilman (1999), os materiais jogados no mar têm como tempo médio de decomposição as seguintes cifras: papel e papelão- 3 meses; sacos plásticos -35 anos; copos de plástico - 50 anos; latas de ferro - 50 anos; isopor - 820 anos; garrafas de vidro - um milhão de anos. Esses dados, sugerem a necessidade de mudança no modo de valorização dos recursos naturais, com 
estratégias que favoreçam tanto o ser humano, outros seres vivos como a natureza. Aproveitando-a, com respeito e cuidado, e sabendo retribuí-la, para que, assim possa se ter uma troca, beneficiando as duas partes.

\section{5 - Costão do Santinho/Museu ao Ar Livre}

No costão do Santinho, pode-se observar a formação rochosa na porção norte da ilha. Neste ponto é realizado uma caminhada na praia, até a chegada no início da trilha do costão do Santinho que é sinalizada e contem totens com informações da civilização que ali habitaram a cerca de 4 mil anos. A trilha leva a ao Museu ao Ar Livre que contem pinturas rupestres com datações de até 4mil anos antes do presente e esculturas, esta última simbolizando a presença de povos indígenas que habitaram a ilha anterior a sua colonização.

Figura 3 - Vegetação litorânea e esculturas dos Povos Sambaquieiros.

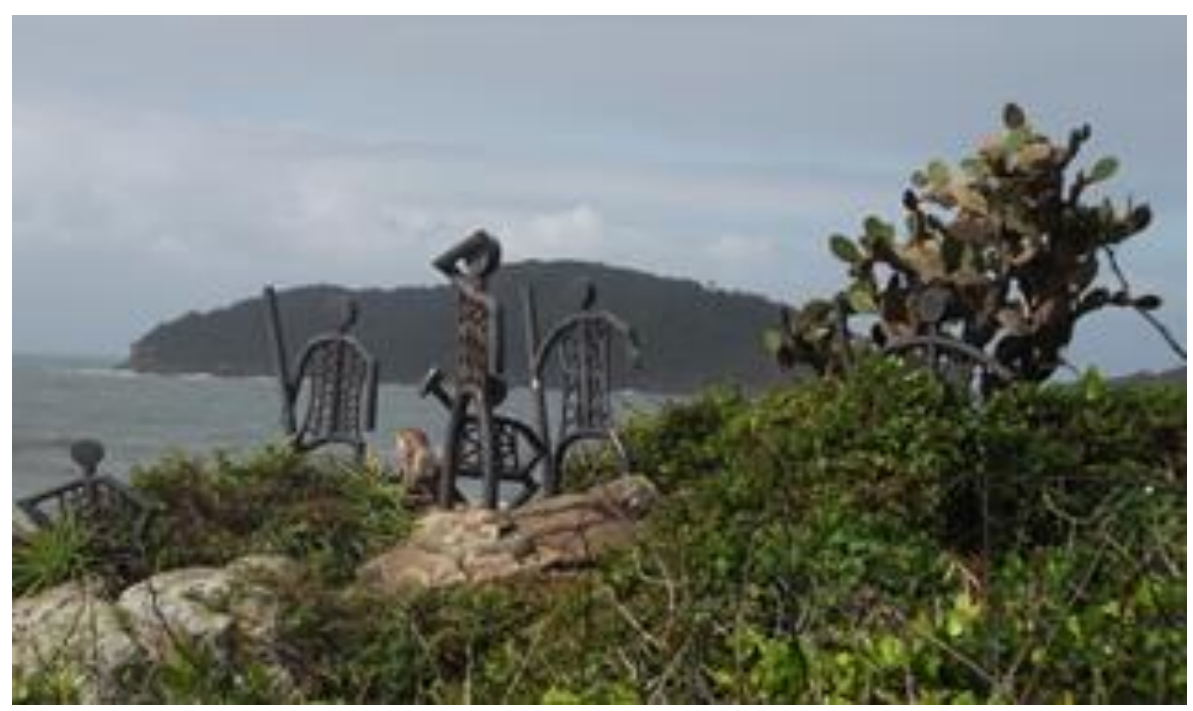

Fonte: Os autores (2018)

\subsection{Parque do Rio Vermelho}

A visita ao Parque do Rio Vermelho objetivou desenvolver com os discentes mais uma vez, os conceitos utilizados pelas Unidades de Conservação. O Parque Estadual do Rio Vermelho é aberto à visitação a todo público e abriga amostras 
da floresta ombrófila densa, a manutenção da vegetação de restinga, quando explicamos a importância para a fixação de dunas. A vegetação de restinga se constitui de extrema importância para as tartarugas que preferem desovar no início da vegetação que tem uma maior proteção para os ninhos que podem estar suscetíveis as dinâmicas das marés.

Um tema interessante com relação ao Parque do Rio Vermelho e que chama atenção dos discentes é que apenas cerca de $11 \%$ da área é constituída de mata nativa o restante da área encontra-se alterado devido ao plantio de pinos (pinheiro-americano) e eucalipto anos atrás. Atualmente, é possível identificar que a invasão destas espécies vegetal (por ação antrópica) reflete-se na ausência de espécies animais que não fazem uso dos recursos destas plantas (pinos e eucalipto) para a sua sobrevivência. Logo, fica evidente a presença de animais de pequeno porte como o lagartinho-da-praia (Liolaesmus occipitalis), uma espécie rara, ameaçada de extinção que vive somente nas dunas do litoral de Santa Catarina e do Rio Grande do Sul, Gambá (Didelphis auritas) e do cachorro-domato (Cerdocyon thous) nos arredores da restinga.

Mesmo com as alterações evidentes na paisagem da Ilha de Santa Catarina ao longo da sua história, há um predomínio de uma matriz natural caracteriza pela Floresta Atlântica, atualmente modificada e identificada como floresta secundária. Sob o domínio da Floresta Ombrófila Densa, o bioma se caracteriza ao longo da paisagem do litoral brasileiro, coberto por uma formação florestal que recebe diferentes denominações, tais como: floresta latifoliada tropical úmida de encosta, mata pluvial tropical e Mata Atlântica ou Floresta Atlântica. Todo esse complexo de paisagem é atualmente muito diverso, principalmente nas áreas planas, as mais ocupadas e transformadas por processos de urbanizações diversos, sendo possível, desta forma, observar essas alterações socioambientais durante a realização do trabalho de campo de Biogeografia em Florianópolis. 


\section{CONCLUSÃO}

Por fim, as reflexões tidas a partir do trabalho de campo mostram o quanto ainda o trabalho de campo pode ser uma proposta metodológica fundamental para a compreensão das transformações do território em seus vários aspectos sociais, culturais, e econômico, e nesse sentido, entender como essas transformações se materializam nos lugares, sendo esse tipo de trabalho essencial para a formação de profissionais da críticos e reflexivos acerca da geografia, na perspectiva da práxis.

É importante considerar que a biogeografia possui técnicas especificas de análises ecossistêmicas que tem por objetivo, a tendência para o conhecimento dos métodos e leis adequadas que geram a dinâmica, também a indução do uso racional pelo homem do espaço e de seus recursos naturais, ainda que desta mesma paisagem.

Diante deste estudo a percepção, tornou-se maior em relação à compreensão das ações e atividades ecológicas, proporcionando soluções mais eficientes para com o manejo referente aos recursos naturais, possibilitando a redefinição do equilíbrio da natureza.

A distribuição de diferentes organismos e espécies de vegetação espalhados, desperta para uma curiosidade para muitos ambientalistas, biólogos e biogeográficos, isso vem acontecendo a um bom tempo. Os mesmos buscam descrever modelos geográficos, para compreender como ocorre a disseminação, e posterior explicação de sua distribuição.

Esta tarefa associada à preocupação de uma decorrência natural influenciada pelo impasse em que a população atual se encontra, trata desta questão com afinco e finalidade de encontrar alternativas que possibilitem o direcionamento ideal para com as práticas exercidas sobre a natureza.

Assim não podemos esquecer-nos de perceber que os seres humanos são parte complementar do ecossistema. Contudo, o ecossistema tem sido avaliado 
como unidade principal nos estudos que abordam a biosfera especificamente no foco ecológico, fator este responsável pela instigação ao pensamento biogeográfico a passar a um novo e influente impulso.

\section{REFERÊNCIAS}

BERTRAND, G. Paisagem e Geografia física global. Esboço metodológico. Curitiba, ed. UFPR, n8, p.141-152, 2004.

CALLAI, H. C.; MORAES, M.M. Educação Geográfica, cidadania e cidade. ACTA Geográfica, Boa Vista, Edição Especial 2017. pp.82-100.

CALLAI, H. C. A formação do profissional em geografia: o professor. ljuí: Ed. UNIJUÍ, 2013.

CARUSO, M.M.L. O desmatamento da Ilha de Santa Catarina de 1500 aos dias atuais. Florianópolis: Ed. UFSC, 1990.

FERRETTI, O. E. Os espaços de natureza protegida na Ilha de Santa Catarina, Brasil. 2013. Tese (Doutorado em Geografia). Universidade Federal de Santa Catarina, Florianópolis, 2013.

FURLAN, S. A. Técnicas de Biogeografia. In: VENTURI, L. A. B. Praticando Geografia: Técnicas de campo e laboratório. São Paulo: Oficina de Textos, 2005.

GIL, A. C. Métodos e técnicas de pesquisa. 6.ed. São Paulo: Atlas, 2008.

AUTOR. Caminhos da Biogeografia. Caminhos da Geografia. Uberlândia. V.17, n.58, p. 168-179. Junho. 2016.

PIMENTA, S. G. O estágio na formação de professores: unidade teoria e prática?. 5.ed. São Paulo: Cortez, 2009.

SILVA, J.L.; FERREIRA, F.A. Um recorte sobre a caracterização física e potencial geoecológico. Revista Geonorte. Edição Especial, V.3, N.4, p. 1306-1319, 2012.

SILVA, J.L. Os desdobramentos e conflitos da criação do Parque sob a ótica do modelo GTP (Geossistema-Território-Paisagem). 2014. 192f. Dissertação (Mestrado em Geografia) Faculdade de Ciências e Tecnologia, Universidade Estadual Paulista, Presidente Prudente, 2014.

SCHEIBE, L.F. \& TEIXEIRA, V.H. Mapa Geológico da Ilha de Santa Catarina, 1970. 
VENTURI, L. A. B. A Técnica e a Observação na Pesquisa. In: VENTURI, L. A. B. (Org.) Práticas de Campos, Laboratório e Sala de Aula. São Paulo: Editora Sarandi, 2011.

\footnotetext{
' Quando mencionarmos neste texto profissional da Geografia estamos nos referindo a GeógrafosProfessores.
}

\begin{abstract}
ii A análise geográfica é uma categoria significava para interpretar o mundo a partir de um olhar espacial. Este olhar suscita ver a complexidade dos fenômenos para além daquilo que é possível enxergar. Por isso, esta categoria emerge como um suporte teórico que possibilita a leitura de mundo. $\mathrm{Na}$ Geografia, esse suporte "tem em si um conjunto de conceitos, e para trabalhar com eles exige-se a clareza do seu significado e do que possam representar no contexto dos conteúdos tratados" (CALLAl, 2013, p. 94).
\end{abstract}

iii Os sambaquis são depósitos de conchas e restos de vidas marinhas, ou seja, materiais orgânicos e calcários, construídos pelo ser humano, como depósito de materiais descartáveis, sem uso. Trata-se, portanto, da sobreposição e empilhamento destes ao longo do tempo. Logo, se constituem enquanto registro fóssil e arqueológico de materiais que serviam de alimentos e eram utilizados pelos povos que naquela localizada habitavam.

iviv Popularmente conhecida como Lagoa da Conceição, porém, o correto é laguna, devido ao seu acesso ao mar na porção norte que permite o fluxo de água doce e salgada. O Lagoa do Peri, não possui acesso ao mar.

v Existem diferenças entre as definições e usos dos termos conservação e preservação. Entretanto, geralmente elas são empregadas como sinônimos. Conservação é o conjunto de diretrizes planejadas para o manejo e utilização sustentada dos recursos naturais, a um nível ótimo de rendimento e preservação da diversidade biológica, enquanto preservação tende a compreender a proteção da natureza, independentemente do interesse utilitário e do valor econômico que possa conter. Definido os conceitos, compreende-se a antagonismo de definições das áreas ambientais do Brasil. As chamadas UCs (Unidades de conservação), dependendo de sua classificação, apresentam equívocos, já que algumas têm proteção integral, de caráter preservacionista, enquanto são denominadas oficialmente como conservacionistas.

vi Informação disponível no Ministério do Meio Ambiente < http://www.mma.gov.br/areasprotegidas/unidades-de-conservacao/criacao-ucs.html>

vii Informações disponível no site do Projeto Tamar < http://www.tamar.org.br/>. 